\title{
Surgical strategies for zone $2 / 3$ pathologies of the thoracic aorta: Resolve or prepare?
}

\author{
Martin Misfeld, MD, PhD, and Michael A. Borger, MD, PhD
}

\author{
From the University Clinic of Cardiac Surgery, Heart Center, University of Leipzig, Leipzig, Germany. \\ Disclosures: Authors have nothing to disclose with regard to commercial support. \\ Received for publication Feb 13, 2018; accepted for publication Feb 13, 2018; available ahead of print March 8 , \\ 2018. \\ Address for reprints: Michael A. Borger, MD, PhD, Leipzig Heart Center, University of Leipzig, Struempell- \\ strasse 39, Leipzig 04289, Germany (E-mail: michael.borger@helios-kliniken.de). \\ J Thorac Cardiovasc Surg 2018;155:2299-300 \\ $0022-5223 / \$ 36.00$ \\ Copyright (C) 2018 by The American Association for Thoracic Surgery \\ https://doi.org/10.1016/j.jtcvs.2018.02.034
}

Surgical strategies to address pathologies of the distal aortic arch and proximal descending aorta (ie, zones 2 and 3) should be made on an individual basis. Concomitant cardiac pathologies, the extent of aortic involvement, and presence of comorbidities should be taken into account when deciding on the optimal choice between 1 of 4 approaches: median sternotomy, lateral thoracotomy, clamshell incision, or hybrid procedure with thoracic endovascular aortic repair (TEVAR).

In this issue of the Journal, Joo and colleagues ${ }^{1}$ report a single-center experience of 229 patients with zone 2/3 aneurysms. Surgery was performed via sternotomy in 98 patients, via thoracotomy in 84 , and as a hybrid approach with TEVAR in 47 patients. In-hospital mortality and stroke rate were significantly lower in patients operated via sternotomy. With the exception of vocal cord palsy, the hybrid approach was not associated with better clinical outcomes compared with the other 2 more invasive procedures. In addition, patients operated via sternotomy showed better long-term survival. The authors concluded that the sternotomy approach is the superior option for patients with zone 2/3 aneurysms.

Aortic pathologies of zone $2 / 3$ are most often associated with additional pathologies of the heart and/or aorta. The incidence of multiple aortic segmental involvement is high, depending on the etiology and location of the "culprit" lesion. ${ }^{2}$ It is therefore important to determine whether an operation can resolve the pathology, or whether the surgeon needs to prepare for a second stage procedure.

Conventional surgery via sternotomy involves the conventional elephant trunk (CET) procedure-first introduced by Hans Borst in $1983^{3}$ - and its more recent modification, the frozen elephant trunk (FET). ${ }^{4}$ The latter can be used for definitive treatment of zone $2 / 3$ pathologies or for the preparation for subsequent TEVAR treatment, if the distal aorta shows residual pathologies or is at increased risk for subsequent interventions. ${ }^{5}$ The CET procedure always requires a second step for definitive cure, either by conventional surgical repair via thoracotomy or with TEVAR completion. However, TEVAR insertion into a FET graft is technically more straightforward than into a CET graft.

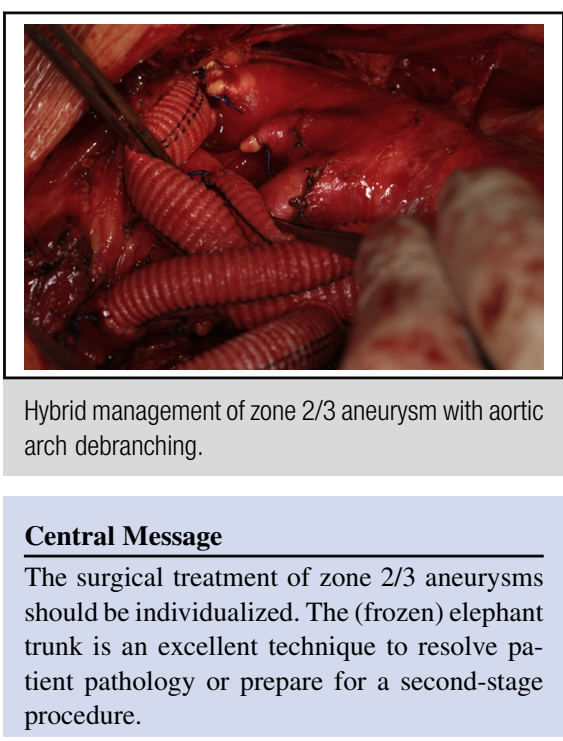

See Article page 2289.

For isolated pathologies of zone $2 / 3$, the FET technique is our preferred approach. Although we initially observed increased rates of paraplegia with the FET procedure, several precautions have since been implemented to decrease the risk of this catastrophic event. ${ }^{7}$ For those patients with extensive aortic pathologies, especially young patients, we advocate conventional second-stage surgery via a thoracotomy or thoracoabdominal approach. As demonstrated in the analysis by Joo and colleagues, ${ }^{1}$ the rate of reintervention in such patients is quite high after TEVAR completion. In select zone $2 / 3$ patients with severe comorbidities, a hybrid approach may be a good alternative. As current stent grafts are not designed for the curved aortic arch, however, the risks of iatrogenic aortic dissection and endoleaks are considerable. ${ }^{8}$ The development of branched aortic arch grafts may lead to improved outcomes compared with hybrid approaches, but substantially more data are required.

The paper by Joo and colleagues ${ }^{1}$ demonstrates that an individualized approach to treat zone $2 / 3$ pathologies can lead to very good clinical outcomes. The CET and, particularly, FET techniques offer an excellent option to either resolve the pathology or to prepare the patient for a second-stage procedure. Hybrid procedures should be reserved for those patients who are not surgical candidates, at least until improvements in stent technology have been achieved. 


\section{References}

1. Joo H-C, Youn Y-N, Lee S-H, Lee S, Chang B-C, Yoo K-J. Clinical outcomes of different surgical approaches for proximal descending thoracic aneurysm involving the distal arch. J Thorac Cardiovasc Surg. 2018;155:2289-98.e1.

2. Crawford ES, Coselli JS, Svensson LG, Safi HJ, Hess KR. Diffuse aneurysmal disease (chronic aortic dissection, Marfan, and mega aorta syndromes) and multiple aneurysm. Ann Surg. 1990;211:521-37.

3. Borst HG, Walterbusch G, Schaps D. Extensive aortic replacement using the "elephant trunk" prosthesis. Thorac Cardiovasc Surg. 1983;31:37-40.

4. Karck M, Chavan A, Hagl C, Friedrich H, Galanski M, Haverich A. The frozen elephant trunk technique: a new treatment for thoracic aortic aneurysms. J Thorac Cardiovasc Surg. 2003;125:1551-3.

5. Idrees JJ, Roselli EE, Wojnarski CM, Feng K, Aftab M, Johnston DR, et al. Prophylactic stage 1 elephant trunk for moderately dilated descending aorta in pa- tients with predominantly proximal disease. J Thorac Cardiovasc Surg. 2015; 150:1150-5.

6. Leontyev S, Borger MA, Etz CD, Moz M, Seeburger J, Bakhtiary F, et al. Experience with the conventional and frozen elephant trunk techniques: a singlecentre study. Eur J Cardiothorac Surg. 2013;44:1076-82.

7. Leontyev S, Tsagakis K, Pacini D, Di Bartolomeo R, Mohr FW, Weiss G, et al. Impact of clinical factors and surgical techniques on early outcome of patients treated with frozen elephant trunk technique by using EVITA open stent-graft: results of a multicentre study. Eur J Cardiothorac Surg. 2016;49:660-6.

8. Luehr M, Etz CD, Lehmkuhl L, Schmidt A, Misfeld M, Borger MA, et al. Surgical management of delayed retrograde type A aortic dissection following complete supra-aortic de-branching and stent-grafting of the transverse arch. Eur J Cardiothorac Surg. 2013;44:958-63. 